\title{
Alcohol Sensor for Safe Driving
}

\author{
Dr. Meena Chavan ${ }^{1}$, Ms. Smita V Khogare ${ }^{2}$, \\ Bharti Vidyapeeth (Deemed To Be University) \\ College of Engineering Pune.
}

\begin{abstract}
Todays vehicles contain hundreds of circuits and electrical components. To have flexible communication among all these components multiplexing is important. Multiplexing plays an important role in working of a vehicle and makes vehicle more efficient. Similarly developing safety measures to prevent drunk and drowsy driving is also a major challenge for car industry. In last five years near about 61 percent of people lost their lives on highways. Alcohol was the factor in most of these cases. In order to increase the safety on roads it is necessary to provide a system which prevent the drunken person from driving the vehicle. In this project alcohol ignition lock is placed in front of the driver seat. The sensor will lock the ignition after detecting the alcohol beyond the limit. For security of vehicle there is a system in which only car owner can get access to the car by inserting the four digit PIN. This will protect the vehicle from theft.
\end{abstract}

Keywords-.Alcohol sensor, PIC controller, GSM modem.

\section{I.INTRODUCTION}

The purpose behind this project is to provide safety and security to the automobiles like cars, trucks etc. Now a day alcohol is a reason of accidents in almost all countries all over the world. Alcohol detector in the car system is designed for safety of the people inside the car.

Nowadays internet is widely used in any field for many applications. Every electronic item registered with a code and update in database. Every year the number of cases of vehicle theft and missing are being registered. Internet of things (IoT) is a technology can be used to overcome this issue. This project provides a security by inserting a four digit PIN to start ignition of vehicle.

\section{II.BLOCK DIAGRAM}

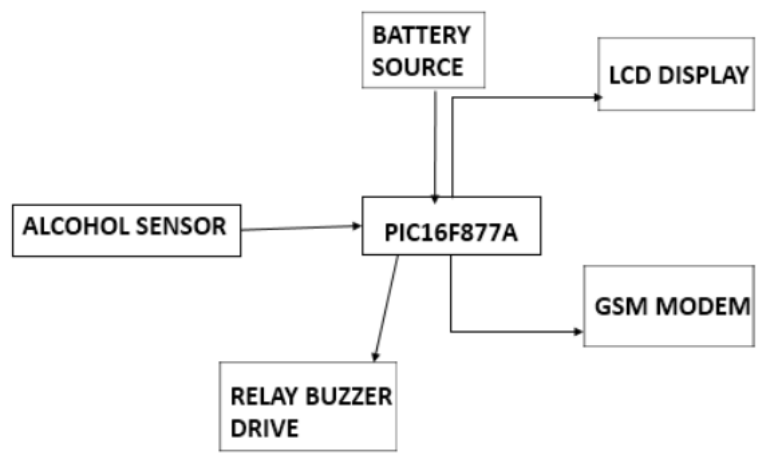

Fig: Block diagram of the system

The main part of the project is an Alcohol sensor. The sensor used in this project is MQ303A. If the alcohol is detected in the breath of the subject then it is detected by the alcohol sensor. MQ303A sensor has fast response to alcohol. Sensor gives this signal to the PIC controller which is the heart of the system. After sensing the alcohol beyond the predetermined level microcontroller send a high pulse to the buzzer. At the same time relay is turned off. Due to this the ignition system is also turned off. A $16 \times 2$ LCD display is interfaced with the controller. The current status of the vehicle and the percentage of alcohol detected by the sensor. GSM modem is also interfaced with IC. The current vehicle update (i.e. alcohol percentage and vehicle status) is send to an authorized person's mobile number.

\section{III.WORKING}

Before starting the vehicle, the driver requires to blow an air into the alcohol sensor which is placed in front of the driver's seat. If the breath sample is below the preset alcohol limit, the vehicle can be started. In this project the percentage of alcohol can be shown by blinking LEDs. If the percentage of alcohol is higher than 50 then buzzer circuit is activated and ignition system is deactivated by the controller. The table below shows the percentage of alcohol and the results.

\begin{tabular}{|c|c|c|}
\hline $\begin{array}{c}\text { Percentage of } \\
\text { alcohol }\end{array}$ & $\begin{array}{c}\text { LED } \\
\text { Status }\end{array}$ & $\begin{array}{c}\text { Vehicle } \\
\text { status }\end{array}$ \\
\hline $0-10$ & Green & Vehicle is ON \\
\hline $10-15$ & Yellow & Vehicle is ON \\
\hline Above 20 & Red & Vehicle is OFF \\
\hline
\end{tabular}

Fig: Table showing vehicle status

Here the circuit requires $12 \mathrm{~V}$ and $5 \mathrm{~V}$ regulated DC supply. The system has $12 \mathrm{~V}$ rechargeable battery and the out of battery is connected to the circuit via switch through GSM modem and relay. LM7805 regulator is used to convert $12 \mathrm{~V}$ into $5 \mathrm{~V}$ regulated DC. The whole system works on the microcontroller. Here the system used PIC16F877A (Peripheral Interface Controller) controller. It is basically used when we need to interface the peripheral devices like LCD display, GSM, buzzer circuits etc. For more security purpose, we can also interface keypad to the controller. The driver can access to the car only by inserting the four digit PIN. This provides the vehicle from theft. The PIC Controller has total five ports out of them four are 8bit ports and one is 3 bit port. PIC works on RICS architecture. To the first port alcohol sensor is connected, it gives the breath sample as an input to the controller. The controller then analyze the input and sends the output to the LCD display and buzzer drive circuit. The LEDs are connected to the second port. Display is connected to the third port and buzzer is connected to the forth port. The program for the project was written in embedded $\mathrm{C}$ then compiled and debug in the PIC controller IC. 


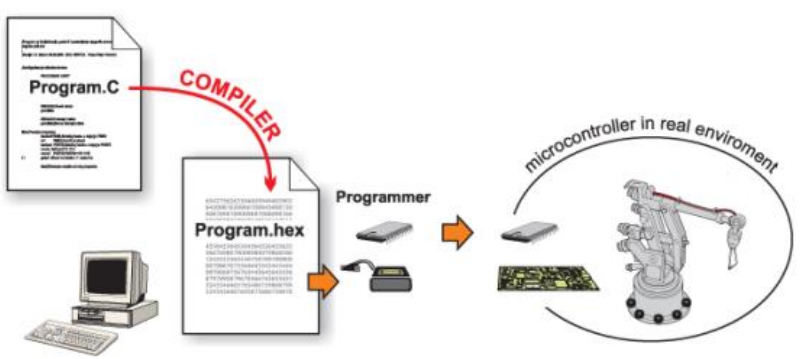

Fig: Processes of compilation of program.

The Proteus software used for the circuit design. Proteus PIC Bundle is complete solution for developing, testing and virtually prototyping your embedded system designs based around microchip technologies series of microcontroller. This software allows you to perform schematic capture and simulate the circuit you design.

\section{IV.RESULTS}

After the circuit design and programming we are ready to start the system. The user will give the key to the vehicle that we design then display will flash the instructions of testing sample in regular intervals and show the status of vehicle. Simultaneously the GSM will send the SMS of vehicle status to the authorized person. Following are some results showing the percentage of alcohol and vehicle status.

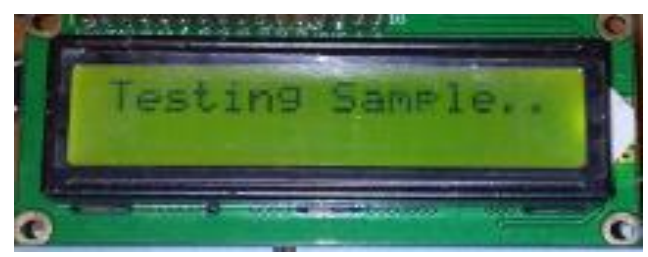

Result 1
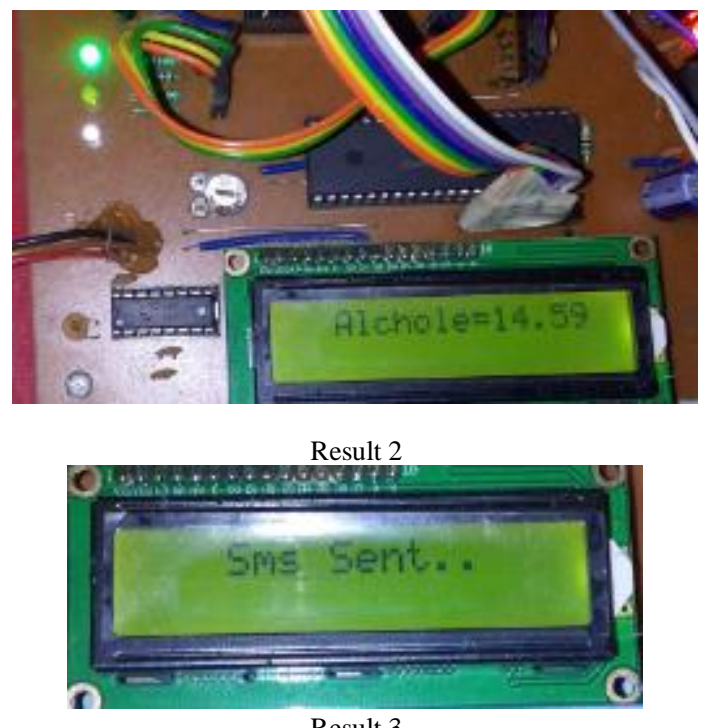

Result 3

The authorized person get the information about the vehicle in the form of SMS as below.

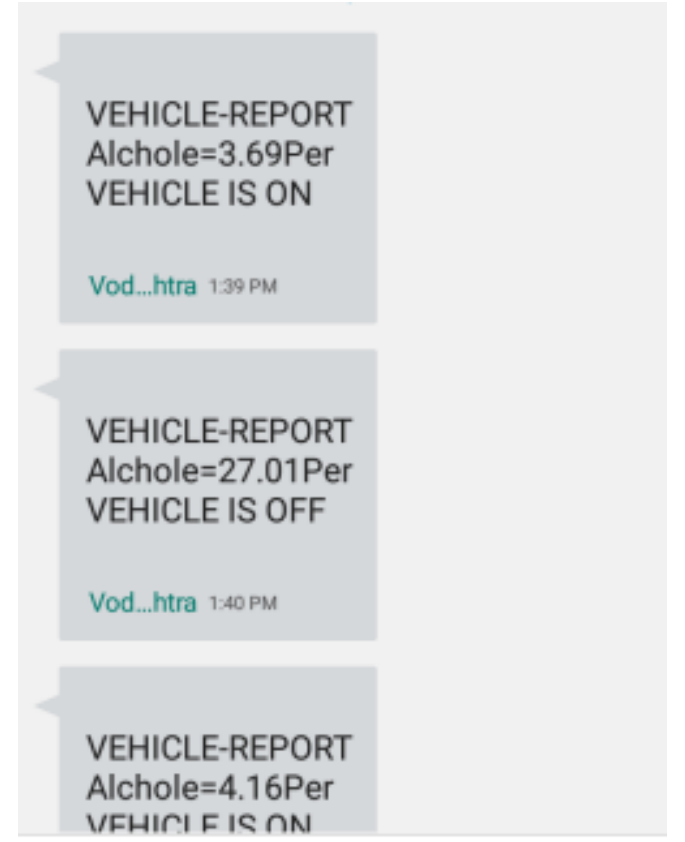

Result 4

\section{V.ADVANTAGES}

1) The components required for the system are cheap and easily available, so the system can be implemented practically.

2) The system is reliable. The driver cannot even tamper it.

3) The circuit requires very less power supply (12V)

\section{VI.CONCLUSION}

By this project we can have safe driving for people and can prevent the vehicle from accident. It can be used wherever the drinking is not authentic. The components used in this project are cheap and can be easily available thus we can use this system for almost all vehicles in city and prevent drunken driving.

\section{REFERENCES}

[1] K. Honda, Sleep and Sleep Science: An Approach to Sleep Improvement and Sleep-Monitoring Technology. Tokyo: CMC Publishing Co., Ltd, 2007, p. 102

[2] M. Sakairi and M. Togami, "Use of water cluster detector for preventing drunk and drowsy driving," in Proc. IEEE Sensors., 2010, pp. 141-144.

[3] M.Kausukan, M. Sundaraj "Automatic Drunken Drive Prevention System" International journal of student research in technology \& management vol 2 Mar-April 2014

[4] Pratiksha Bhuta, Karan Desai, Architakeni "Alcohol Detection and vehicle controlling" Department of electronics and telecommunication engineering, Thadomal Sahani engineering college, Bandra. IJETA vol2, issue2 March-april2015. 